\title{
EFFECTS OF AN AGING POPULATION IN SHAANXI PROVINCE ON CONSUMPTION STRUCTURE
}

\author{
Dandan Li \\ International Business School, Shaanxi Normal University, Xi'an 710119, P. R. China \\ Shan Wu \\ International Business School, Shaanxi Normal University, Xi'an 710119, P. R. China
}

\begin{abstract}
In recent years, the trend of the aging of the population is more and more obvious; an aging population has gradually become a problem that cannot be ignored. In view of the aging population in Shaanxi province, we study the influence of the consumption structure analysis on the aging population. At the same time, according to all domestic and foreign scholars for an aging population problem has done deep research, we use the grey correlation analysis method to analyze and discuss the influence of the aging population on consumption structure in Shanxi Province. Then, we put forward some countermeasures and suggestions.
\end{abstract}

Key words: Shaanxi Province; Aging population; Consumption structure; Gray correlation degree

JEL code: D12, J14

\section{Introduction}

\section{(1) The background of the topic}

The formation of an aging population is due to not only the birth rate and mortality rate, but also to a considerable extent, it is also a result of economic development, technological progress, cultural and educational improvement, and the improvement of medical and health infrastructure. In view of the current situation, although the proportion of the elderly population in developed countries the proportion is higher than that of developing countries, but according to Statistics estimates that by 2040 the world nearly $3 / 4$ of the elderly population in developing countries. Although China entered the stage of population aging from the end of 1999, but its aging showed a severe trend of change, also directly increased the burden of economic and social development. 
At present, the market system for the elderly has not yet been established, the overall elderly market is still in a state of development, and the huge consumer demand for the elderly population has not yet been met. Population aging is a new and valuable research field, and reference materials are very limited. Most related articles are the impact of population aging on the overall socio-economic development brought about or predict trends such as an aging population. However, there are few articles to analyze the problem of population consumption structure in the aging population. Therefore, it is necessary to deepen the study of the impact of the aging population on the consumption structure under the phenomenon of population aging.

\section{(2) The significance of the study}

Theoretically speaking, at present, there are some researches on the relationship between aging population, consumption structure of residents and consumption behavior in china. However, most of these studies are only on the qualitative level, and few of them quantitatively analyze by means of related statistical methods. According to the above, based on existing research at home and abroad on the consumption structure, we use the method of gray relational analysis to analyze the social and economic impact of the elderly population on the consumption structure in Shaanxi Province with population aging from the perspective of theoretical research.

Truly speaking, China's population base is relatively large, and the aging of the population's age structure arises from the fact that the whole society is less wealthy. This shows that China's population aging is different from the developed countries in Western countries; it has both the universality of population aging and its own particularity. As for the current situation in Shaanxi Province, its population aging is slightly lower than the national average. However, according to the forecast results, the process of population aging in Shaanxi will continue to accelerate, and the aging trend of the population will become more and more obvious. We study the relationship between the elderly population and consumption structure in the process of population aging in Shaanxi Province, which will be of great significance to the population and economic and social development of Shaanxi Province and Northwest China.

\section{Literature Review}

The aging of the western developed countries started early and developed relatively stable. Therefore, the academic circles abroad also began early focus on the relationship between population aging and social economic development. But until about 1940, Western scholars began to really focus on the aging population and consumption issues due to the outbreak of 
the economic crisis and the deepening of the aging population in western countries.

American economist Modigliani (1954) put forward "Life-cycle hypothesis": The consumer will optimize the expected total income of each age group according to the principle of utility maximization. With regard to the study of the consumer behavior and market of the elderly population, Richard C Eventual (1990) divides the aged consumer market into four levels according to the age of the elderly: Low age (55-64 years), light age (65-74 years), middle age (75-84 years old) and advanced age ( 85 years old and above). Li and Gao (2008) find that the aging of the population will further influence the change of consumption structure by using the grey correlation degree calculation method. Jin (2012) predicts the demand level and total consumption of elderly consumers in the future, and finds that the consumption market of the elderly population is likely to become a new economic growth point to stimulate domestic demand. Chao (2012) expounds the impact of population aging on consumption structure in more detail, including health care, food, clothing industry three aspects. Wang and Lei (2013) put forward countermeasures to solve the problem of increasing number of elderly through the analysis of the consumption situation in the background of aging. Gong et al. (2015) analyzed the influence of population aging on consumption in Beijing by multiple regression analysis.

Based on the existing research at home and abroad, we take the consumption structure as the basic starting point to make a comprehensive and specific analysis and study of the population aging in Shaanxi province.

\section{Gray Correlation Analysis aging population and consumption structure in Shaanxi province}

\subsection{Gray correlation analysis method introduced}

The grey correlation model quantitatively describes the relative change between the two systems or systems within two factors. It is mainly used to measure the degree of correlation between the systems or factor, that is, the size is related to the change in direction, velocity, etc. In the process of system development, we can use gray correlation degree to analyze which is the main influencing factor, according to the obtained value to judge, if the value is relatively large, then it is the main influencing factors, if the value is relatively small, its impact is relatively small. Gray may be established correlation matrix through the following steps: 
(1) Establish comparison sequences and reference sequences

Let the reference sequence be:

$$
Y_{\mathrm{i}}=\left\{\mathrm{y}_{\mathrm{i}}(1), \mathrm{y}_{\mathrm{i}}(2), \cdots, y_{i}(n)\right\},(j \in J=\{1,2, \cdots, s\})
$$

Let the comparison sequence be:

$$
X_{\mathrm{j}}=\left\{\mathrm{x}_{\mathrm{j}}(1), \mathrm{X}_{\mathrm{j}}(2), \cdots, \mathrm{x}_{\mathrm{j}}(\mathrm{n})\right\}, \quad(\mathrm{i} \in I=\{1,2, \ldots, \mathrm{m}\})
$$

The corresponding multi - reference sequence is gray - relational factor set:

$X \cup Y=\left\{V_{\mathrm{i}}, X_{\mathrm{i}} \mid \mathrm{j} \in J=\{1,2, \ldots, \mathrm{s}\}, \quad \mathrm{i} \in I=\{1,2, \ldots, \mathrm{m}\}\right\}$

among them $X=\left\{X_{1}, X_{2}, \cdots, X_{\mathrm{m}}\right\}, \quad Y=\left\{Y_{1}, Y_{2}, \cdots, Y_{\mathrm{s}}\right\}$

(2) Sequence index value, i.e. dimension treatment

For non-dimensional time series data processing method, the initial value of the main conversion and equalization transformation. In this paper, we only use the mean transform to carry out dimensionless processing on the reference and comparison sequences.

Reference sequence $Y_{\mathrm{i}}$ the average value is $\overline{\mathrm{y}}_{\mathrm{i}}$, which is $\overline{\mathrm{y}}_{\mathrm{i}}=\frac{1}{\mathrm{n}} \sum_{\mathrm{k}=1}^{\mathrm{n}} \mathrm{y}_{\mathrm{i}}(k)$ 。

Of the value of the $y_{i}(k)$ is $y_{i}^{\prime}(k)$, then $y_{i}^{\prime}(k)=y_{i}(k) / \frac{y_{i}}{}$.

The average of the comparison sequences $X_{j}$ is $\overline{\mathrm{X}_{\mathrm{j}}}$, which is $\overline{\mathrm{X}_{\mathrm{j}}}=\frac{1}{\mathrm{n}} \sum_{\mathrm{k}=1}^{\mathrm{n}} \mathrm{X}_{\mathrm{j}}(\mathrm{k})$ 。

Of the value of the $\mathrm{X}_{\mathrm{j}}^{(\mathrm{k})}$ is $x_{j}^{\prime}(k)$, then $x_{j}^{\prime}(k)=x_{j}(k) / \frac{1}{x_{j}}$

(3) Define the difference information set $\Delta$

$$
\Delta=\left\{\Delta_{i j}(k)\left|\Delta_{i j}(k)=\right| y_{i}^{\prime}(k)-x_{j}^{\prime}(k) \mid, i \in I=\{1,2, \cdots, m\}, j \in J=\{1,2, \cdots, s\}, k \in K=\{1,2, \cdots, n\}\right\}
$$


(4) Define the gray relational difference information space $\Delta_{G R}$

$$
\begin{aligned}
& \Delta_{G R}=\left\{\Delta, \delta, \Delta_{\mathrm{ij}}(\max ), \Delta(\min )\right\}, \\
& \Delta(\max )=\max _{i} \max _{j} \max _{k} \Delta_{i j}(k), \Delta(\min )=\min \min _{j} \min _{k} \Delta_{i j}(k) 。
\end{aligned}
$$

(5) Gray correlation coefficient

$$
r\left(y_{i}^{\prime}(k), x_{j}^{\prime}(k)\right)=\frac{\Delta(\min )+\delta \Delta(\max )}{\Delta_{i j}(k)+\delta \Delta(\max )} 。
$$

$\delta$ is the resolution factor, and there is too much to attenuate the impact of the correlation coefficient distortion. $\delta$ smaller, the better the resolution, when the resolution is generally considered the best, generally a value of 0.5 .

(6) Gray correlation degree

Comparison with a reference sequence using the mean correlation coefficient of each sequence to measure the degree of sequence relatedness. For the j-th degree of association with the i-th sequence comparison a reference sequence.

$$
\mathbf{r}_{i j}=r\left(y_{i}, x_{j}\right)=\frac{1}{n} \sum_{k=1}^{n} r\left(y_{i}^{\prime}(k), x_{j}^{\prime}(k)\right)
$$

(7) Gray find correlation matrix R

$$
R=\begin{array}{cccc}
\boldsymbol{r}_{11} & \boldsymbol{r}_{12} & \cdots & \boldsymbol{r}_{1 s} \\
\boldsymbol{r}_{21} & \boldsymbol{r}_{22} & \cdots & \boldsymbol{r}_{2 s} \\
\vdots & \vdots & \ddots & \vdots \\
\boldsymbol{r}_{m 1} & \boldsymbol{r}_{m 2} & \cdots & \boldsymbol{r}_{m s}
\end{array}
$$




\subsection{Gray Correlative Degree Analyses on the Influence of Aging Population on Consumption Structure}

(1) Related data collation

The age data using over 65 years of age and the proportion of the total population to be related to the empirical analysis and research. According to the statistical data of the elderly in 2009, the relevant data of the elderly population can provide the proportion of the aged population of the towns and villages in Shaanxi Province from 2005 to 2012, as shown in Table 3-1 below.

Table 3-1.

\begin{tabular}{|l|c|c|c|c|c|c|c|c|}
\hline \multicolumn{6}{|c|}{ Shaanxi Province from 2005 to 2012 the proportion of the elderly population } \\
\hline $\begin{array}{c}65 \text { years old } \\
\text { and above }\end{array}$ & 8.58 & 8.60 & 8.96 & 8.97 & 9.11 & 8.53 & 8.71 & 8.97 \\
\hline
\end{tabular}

(2) The division of consumption structure and the selection and source of data

According to the basic situation of the consumption expenditure of the residents of Shaanxi Province, we divide the consumption structure into the following eight categories: food, housing, clothing, educational entertainment services, household equipment supplies and services, transportation and communication, Health care, other goods and services. According to the statistical data of per capita expenditure of each consumption structure from 2005 to 2012, we obtained the proportion of consumption structure of urban residents and rural residents in Shaanxi Province by the statistical yearbook of Shaanxi Provincial Bureau of Statistics in 2013. The detailed data is as following in Table 3-2 and Table 3-3. 
Table 3-2

\begin{tabular}{|lcccccccc|}
\hline \multicolumn{2}{|c|}{ 2005-2012 per capita household consumption expenditure proportion of urban residents in Shaanxi Province } \\
unit : $\%$
\end{tabular}

Table 3-3

\begin{tabular}{|c|c|c|c|c|c|c|c|c|}
\hline \multicolumn{9}{|c|}{ 2005-2012 rural residents per capita household consumption expenditure in Shaanxi Province unit $: \%$} \\
\hline year & food & clothes & live & $\begin{array}{l}\text { Household } \\
\text { equipment } \\
\text { and services }\end{array}$ & $\begin{array}{l}\text { medical } \\
\text { insurance }\end{array}$ & $\begin{array}{l}\text { Traffic and } \\
\text { communicati } \\
\text { ons }\end{array}$ & $\begin{array}{c}\text { Education } \\
\text { and cultural } \\
\text { entertainmen } \\
\text { t services }\end{array}$ & other \\
\hline 2005 & 42.90 & 6.50 & 11.20 & 4.40 & 8.80 & 8.60 & 15.70 & 2.00 \\
\hline 2006 & 39.00 & 6.40 & 15.60 & 4.40 & 9.00 & 9.90 & 13.60 & 2.20 \\
\hline 2007 & 36.80 & 6.30 & 20.00 & 4.20 & 8.70 & 10.00 & 11.90 & 2.20 \\
\hline 2008 & 37.40 & 5.90 & 20.10 & 5.20 & 8.40 & 9.10 & 11.80 & 2.00 \\
\hline 2009 & 35.10 & 6.20 & 20.80 & 5.90 & 9.80 & 9.00 & 11.30 & 1.90 \\
\hline 2010 & 34.20 & 6.30 & 22.10 & 6.10 & 9.90 & 8.90 & 10.50 & 2.00 \\
\hline 2011 & 30.00 & 6.30 & 24.70 & 6.20 & 11.90 & 9.10 & 9.00 & 2.80 \\
\hline 2012 & 29.70 & 6.50 & 24.60 & 5.80 & 12.10 & 9.80 & 8.70 & 2.70 \\
\hline
\end{tabular}

(3) Gray Relational Grade Calculation of Aging Population and Expenditure on Consumption Structure

According to the method of the gray relational analysis, we use the data series in Table 3-1 as the reference series, the data series in Table 3-2 and Table 3-3 as the comparison series 1 and the comparison series 2 . In addition, we use gray system software for empirical analysis, and then the mean sequence method to do the dimensionless processing of the reference sequence 
and the comparison sequence 1 and the comparison sequence 2 respectively. The scaled data is as Table 3-4 and Table 3-5 below:

Table 3-4

\begin{tabular}{|c|c|c|c|c|c|c|c|c|c|}
\hline & $\begin{array}{c}\text { Target } \\
\text { value of } \\
\text { the }\end{array}$ & \multicolumn{8}{|c|}{ Compare the non-dimensional results of sequence 1} \\
\hline year & $\begin{array}{c}65 \text { years } \\
\text { old and } \\
\text { above }\end{array}$ & food & clothes & live & $\begin{array}{l}\text { Househol } \\
\qquad \mathrm{d} \\
\text { equipmen } \\
\mathrm{t} \text { and } \\
\text { services }\end{array}$ & $\begin{array}{l}\text { medical } \\
\text { insurance }\end{array}$ & $\begin{array}{l}\text { Traffic } \\
\text { and } \\
\text { communi } \\
\text { cations }\end{array}$ & $\begin{array}{c}\text { Education } \\
\text { and } \\
\text { cultural } \\
\text { entertain } \\
\text { ment } \\
\text { services }\end{array}$ & other \\
\hline 2005 & 1 & 1 & 1 & 1 & 1 & 1 & 1 & 1 & 1 \\
\hline 2006 & 1 & 0.95 & 1.01 & 1.01 & 1.13 & 0.32 & 0.42 & 0.38 & 0.34 \\
\hline 2007 & 1.04 & 1.01 & 1.07 & 1.01 & 1.09 & 0.32 & 0.39 & 0.32 & 0.4 \\
\hline 2008 & 1.05 & 1.02 & 1.06 & 1.05 & 1.13 & 0.35 & 0.38 & 0.29 & 0.41 \\
\hline 2009 & 1.06 & 1.03 & 1.12 & 0.97 & 1.14 & 0.32 & 0.38 & 0.3 & 0.41 \\
\hline 2010 & 0.99 & 1.03 & 1.2 & 0.97 & 1.09 & 0.31 & 0.39 & 0.3 & 0.37 \\
\hline 2011 & 1.02 & 1.01 & 1.2 & 0.89 & 1.18 & 2.61 & 3.43 & 2.47 & 2.99 \\
\hline 2012 & 1.05 & 1 & 1.16 & 0.88 & 1.14 & 0.31 & 0.45 & 0.3 & 0.39 \\
\hline
\end{tabular}

Table 3-5

\begin{tabular}{|c|c|c|c|c|c|c|c|c|c|}
\hline & Reference & \multicolumn{8}{|c|}{ Compare the dimensionless results of sequence 2} \\
\hline year & $\begin{array}{c}65 \text { years } \\
\text { old and } \\
\text { above }\end{array}$ & food & clothes & live & $\begin{array}{l}\text { Househol } \\
\qquad \mathrm{d} \\
\text { equipmen } \\
\mathrm{t} \text { and } \\
\text { services }\end{array}$ & $\begin{array}{c}\text { medical } \\
\text { insurance }\end{array}$ & $\begin{array}{l}\text { Traffic } \\
\text { and } \\
\text { communi } \\
\text { cations }\end{array}$ & $\begin{array}{c}\text { Educatio } \\
\mathrm{n} \text { and } \\
\text { cultural } \\
\text { entertain } \\
\text { ment } \\
\text { services }\end{array}$ & other \\
\hline 2005 & 1 & 1 & 1 & 1 & 1 & 1 & 1 & 1 & 1 \\
\hline 2006 & 1 & 0.91 & 0.98 & 1.39 & 1 & 1.02 & 1.15 & 0.87 & 1.1 \\
\hline 2007 & 1.04 & 0.86 & 0.97 & 1.79 & 0.95 & 0.99 & 1.16 & 0.76 & 1.1 \\
\hline 2008 & 1.05 & 0.87 & 0.91 & 1.79 & 1.18 & 0.95 & 1.06 & 0.75 & 1 \\
\hline 2009 & 1.06 & 0.82 & 0.95 & 1.86 & 1.34 & 1.11 & 1.05 & 0.72 & 0.95 \\
\hline
\end{tabular}


Table 3-5, cont.

\begin{tabular}{|cccccccccc|}
\hline 2010 & 0.99 & 0.8 & 0.97 & 1.97 & 1.39 & 1.13 & 1.03 & 0.67 & 1 \\
\hline 2011 & 1.02 & 0.7 & 0.97 & 2.21 & 1.41 & 1.35 & 1.06 & 0.57 & 1.4 \\
\hline 2012 & 1.05 & 0.69 & 1 & 2.2 & 1.32 & 1.38 & 1.14 & 0.55 & 1.35 \\
\hline
\end{tabular}

According to the data in the above table and the gray correlation coefficient formula $\mathrm{r}_{\mathrm{ij}}(\mathrm{k})=\frac{\mathrm{m}+\xi M}{\Delta_{\mathrm{ij}}(\mathrm{k})+\xi M}, \xi \in(0,1), \mathrm{k}=1,2, \cdots, n$, The gray correlation coefficient between the population aged 65 and above and the consumption structure of urban residents is as follows:

Table 3-6 Gray Correlation Coefficient Table of Consumption Structure of Population and Urban Residents aged 65 and Over in Shaanxi Province

\begin{tabular}{|c|c|c|c|c|c|c|c|c|}
\hline year & $\mathbf{r}_{11}$ & $\mathbf{r}_{12}$ & $\mathbf{r}_{13}$ & $\mathbf{r}_{14}$ & $\mathbf{r}_{15}$ & $\mathbf{r}_{16}$ & $\mathbf{r}_{17}$ & $\mathbf{r}_{18}$ \\
2005 & 1.00 & 1.00 & 1.00 & 1.00 & 1.00 & 1.00 & 1.00 & 1.00 \\
2006 & 0.96 & 0.99 & 0.99 & 0.90 & 0.64 & 0.68 & 0.66 & 0.65 \\
2007 & 0.98 & 0.98 & 0.98 & 0.96 & 0.63 & 0.65 & 0.63 & 0.65 \\
2008 & 0.98 & 0.99 & 1.00 & 0.94 & 0.63 & 0.64 & 0.61 & 0.65 \\
2009 & 0.98 & 0.95 & 0.93 & 0.94 & 0.62 & 0.64 & 0.61 & 0.65 \\
2010 & 0.97 & 0.85 & 0.98 & 0.92 & 0.64 & 0.67 & 0.64 & 0.66 \\
2011 & 0.99 & 0.87 & 0.90 & 0.88 & 0.43 & 0.33 & 0.45 & 0.38 \\
2012 & 0.96 & 0.92 & 0.88 & 0.93 & 0.62 & 0.67 & 0.62 & 0.65 \\
\hline
\end{tabular}

The gray correlation coefficient between the population aged 65 and above and the consumption structure of rural residents is shown in the following table: 
Table 3-7 Gray Correlation Coefficient Table of Consumption Structure of Population and Rural Residents aged 65 and Over in Shaanxi Province

\begin{tabular}{|l|l|l|l|l|l|l|l|l|}
\hline year & $\mathbf{r}_{21}$ & $\mathbf{r}_{22}$ & $\mathbf{r}_{23}$ & $\mathbf{r}_{24}$ & $\mathbf{r}_{25}$ & $\mathbf{r}_{26}$ & $\mathbf{r}_{27}$ & $\mathbf{r}_{28}$ \\
2005 & 1.00 & 1.00 & 1.00 & 1.00 & 1.00 & 1.00 & 1.00 & 1.00 \\
2006 & 0.87 & 0.97 & 0.60 & 1.00 & 0.97 & 0.80 & 0.82 & 0.86 \\
2007 & 0.77 & 0.89 & 0.44 & 0.87 & 0.92 & 0.83 & 0.68 & 0.91 \\
2008 & 0.77 & 0.81 & 0.45 & 0.82 & 0.86 & 0.98 & 0.66 & 0.92 \\
2009 & 0.71 & 0.84 & 0.43 & 0.68 & 0.92 & 0.98 & 0.64 & 0.84 \\
2010 & 0.76 & 0.97 & 0.38 & 0.60 & 0.81 & 0.94 & 0.65 & 0.98 \\
2011 & 0.65 & 0.92 & 0.33 & 0.60 & 0.64 & 0.94 & 0.57 & 0.61 \\
2012 & 0.62 & 0.92 & 0.34 & 0.69 & 0.64 & 0.87 & 0.54 & 0.66 \\
\hline
\end{tabular}

From the above table and table according to the gray correlation formula $\gamma_{\mathrm{ij}}=\frac{1}{\mathrm{n}} \sum_{\mathrm{k}=1}^{\mathrm{n}} \mathrm{r}_{\mathrm{ij}}(\mathrm{k})$, can be 65 years old and above the population and urban residents and rural residents of the gray correlation matrix:

$$
R=\begin{array}{llllllllllllllll}
r_{11} & r_{12} & r_{13} & r_{14} & r_{15} & r_{16} & r_{17} & r_{18} & 0.98 & 0.94 & 0.96 & 0.93 & 0.65 & 0.66 & 0.65 & 0.66 \\
r_{21} & r_{22} & r_{23} & r_{24} & r_{25} & r_{26} & r_{27} & r_{28} & 0.77 & 0.92 & 0.50 & 0.78 & 0.85 & 0.92 & 0.70 & 0.85
\end{array}
$$

That is, the gray correlation degree as follows Table 3-8

Table 3-8

\begin{tabular}{|ccccccccc|}
\hline \multicolumn{7}{|c|}{ The degree of association between the elderly population and the eight categories of consumer goods in } \\
Shaanxi province
\end{tabular}




\section{Conclusions}

From the perspective of the town, the first four consumption data of the consumption of elderly people are food, residence, clothing and household equipment and services. They are most closely related to the consumption of the elderly. Whereas, from the perspective of the rural, the correlation between the elderly population and clothing, transportation, communications, medical care and other four consumption data is relatively high. Overall, the influence of aging population in Shaanxi province on the consumption structure of residents is great in the aspect of food in town; as well as in the aspect of clothes in rural.

At present, the main task of our province in population policy is to control population growth as well as to prevent the process of population aging speeding up and the proportion of the aged population from becoming larger. Therefore, it is necessary to design and develop a long-term population planning that can exist simultaneously and to strengthen some of the strategic research on population development. We should strive for such an ideal state that the pace of population aging will gradually converge with the level of social economic development.

\section{References}

Chao, S. D. (2012), "Study on the influence of population aging on the consumption structure of our country." Economic Review.

Deng, J. L. (2002). "Gray theoretical basis.” Wuhan: Huazhong University of Science and Technology Press.

Gong, Y. H. \& Du, J. Y. \& Song, W. G. (2015), “An analysis of the influence of population aging on consumption in Beijing”. Journal of Beijing Polytechnic College, pp.16-19.

Jin, X. T. (2012), “China's Aging Population Consumption: Status and Trends.” Northwest Population, Volume 3.

Leimer, D R. (1981), "Cohort-Specific Measures of Lifetime Net Social Security Transfers." National Tax Journal,34(1):9-28.

Li, H. X. and Gao, W. (2008), "Gray Relational Analysis of the Impact of Population Aging on Consumption Structure in China." Population and Development, 14 (6).

Mechanisms of Ageing \& Development (2004), Volume 125, Issue 4, pp.285-289.

Richard C Eventual, S. (1990), “The Aging consumer: what's all the fuss about anyway?" The Journal of Services Marketing, Sum.

Statistics Bureau of Shaanxi Province, Compilation of population statistics of Shaanxi province 
(1949-2000), China Statistics Press, pp.210-212.

Statistics Bureau of Shaanxi Province, The fifth Shaanxi census data (first volume), China Statistics Press, pp.62, pp.424-430.

Statistics Bureau of Shaanxi Province, Shaanxi statistical yearbook (2013), China Statistics Press,Sum.

Tang, Y. S. and Zhang, X. (2011), "Effects of factors affecting the scale of affordable housing Taking Changsha City as an example”, Seeking, 2011 (7): 35-38.

Wang, X. M. \& Zhang, J. Z.\& Wang, R. (2001), "Gray System Analysis and Practical Computing Procedure", Wuhan: Huazhong University of Science and Technology Press. 